\title{
LA DOCTRINA DE LA TRINIDAD
}

\author{
Oscar S. Mendoza \\ oscarsmorbegoso@gmail.com \\ Distrito Misionero "Lurín" \\ Asociación Peruana Central
}

Hoy en día, la mala comprensión de la Trinidad, de la divinidad de Cristo y de la persona del Espíritu Santo, tanto en el Antiguo como en el Nuevo Testamento, ha suscitado un pensamiento anti-trinitario en algunos movimientos cristianos.

Por ejemplo, los Testigos de Jehová piensan que la Trinidad no tiene origen bíblico, sino católico y pagano. Para ellos, Jesús es un "dios"

110 creado por el Padre y no igual a Él. También, señalan que el Espíritu Santo es una fuerza y no una persona.

La Escritura, sin embargo, revela: (1) la existencia de la Trinidad; (2) la divinidad de Cristo; y (3) la divinidad y persona del Espíritu Santo. Este asunto es importante tratarlo:

\section{La Trinidad en el Antiguo Testamento}

La Trinidad en el Antiguo Testamento es implícita, a diferencia del Nuevo; y revela la existencia de más de una persona divina.

a. Más de una persona divina participó en la creación del ser humano (Gn 1:26).

b. El ser humano, después de pecar, llegó a ser como la Trinidad; pero, solo en relación al conocimiento del bien y del mal (Gn 3:22).

c. Las mismas tres personas confundieron a los que estaban 
construyendo la torre de Babel (Gn 11:7).

d. David señaló que su Señor habló a su Señor (Sal 110:1).

e. Una de las personas divinas preguntó —en el llamado a Isaíasquién iría de parte de ellos (por supuesto, se dirige a personas que tienen la misma autoridad) — Isaías 6:8.

f. En el Antiguo Testamento, la Trinidad está conformada por:

i. Jehová (el Padre en el NT), que dialoga con el Ángel de Jehová/Dios (1 Cr 21:18; 27).

ii. El Ángel de Jehová/Dios (el Hijo en el NT), que está ante la presencia de Jehová e intercede por el pueblo (Zac 3:2, 5).

iii. El Espíritu de Jehová/Dios (el Espíritu Santo en el NT), que aparece junto con las otras dos personas.

g. Los textos implícitos que registran a estas tres personas, aparecen básicamente en el libro de Isaías:

i. Isaías 42:1: registra a Dios, que envía a su Siervo (el Mesías) —de quien tiene contentamiento (ver Mt 3:17), y que le da el Espíritu.

ii. Isaías 48:16: revela a Jesús estando desde el "principio", y enviado por Jehová Dios y el Espíritu.

iii. Isaías 63:8-10: señala a Jehová, el Dios de Israel; al Ángel de su faz (el de Jehová); y al Espíritu.

\section{La Trinidad en el Nuevo Testamento}

El Nuevo Testamento revela que son tres aquellas personas divinas:

a. En el bautismo del Señor Jesús, aparecen el Padre — hablando 
desde el cielo- y el Espíritu Santo (en forma de una paloma) -Mateo 3:16-17.

b. El creyente es llamado a hacer discípulos en el nombre del Padre, del Hijo y del Espíritu Santo (Mt 28:19).

c. Cristo, antes de regresar al cielo, mencionó que iba a rogar al Padre, para que envíe a "otro Consolador", el Espíritu Santo. Ver Juan 14:16-17.

d. En Hechos 2:33, dice que Jesucristo subió a la diestra del Padre, y que la iglesia recibió el Espíritu Santo.

e. Al finalizar su epístola, Pablo mencionó a la Trinidad (1 Co 13:14).

\section{La divinidad de Jesús en la Escritura}

La Biblia presenta al Señor Jesús como una de las personas de la Trinidad. Como tal, Él es presentado como un Ser eterno, Divino, 112 Creador y Redentor.

Antiguo Testamento

El Ángel de Jehová

Como se mencionó, el Cristo pre-encarnado era el "Ángel de Jehová” (o también "el Mensajero de Jehovâ"). En el AT, a Él se lo describe con atributos divinos y se identifica, a sí mismo, como "Dios".

a. El Ángel de Jehová dialogó con Agar. Al finalizar el diálogo, ella le dijo: "Tú eres Dios" (Gn 16:13. Leer desde el v. 7).

b. El Ángel de Jehová, al dialogar con Abraham, se llama a sí mismo "Jehová" (ver Gn 22:1-2, 12, 15-18).

c. Cuando conversó con Jacob, el Ángel de Jehová se identifica como el "Dios de Beth-Él” (Gn 31:11-13). 
d. Reconociendo que fue Dios quien libró a los hebreos de Egipto e hizo un pacto con ellos, el Ángel de Jehová se responsabilizó de todo ello (Juec 2:1-2).

e. Ante la presencia de Manoa, el Ángel de Jehová recibió adoración (práctica exclusiva para Dios; ver Juec 13:19-21).

f. En el juicio divino, el Ángel de Jehová cumplía la función de intercesor (Zac 3:2-3, 5).

\section{El Mesías}

a. Al Mesías venidero se lo identifica como "Dios fuerte" y "Padre eterno" (Is 9:6).

b. Quien iba a venir, el Mesías, es un Ser eterno, no fue creado (Miq $5: 2)$.

\section{Nuevo Testamento}

a. El Verbo es identificado como Dios, y se indica que fue encarnado y "habitó entre nosotros". Jesucristo es aquel Verbo (Jn 1:1, 14).

b. Considerando el texto original, Juan identifica al Jesucristo como "el Hijo único, que es Dios" (Jn 1:18, énfasis añadido).

c. Tomás identifica a Cristo como "Señor" y "Dios" (Jn 20:28).

d. Es el Creador de todas las cosas (Jn 1:1-3; Col 1:16-17).

e. Pablo identificó a Jesucristo como "Dios" (Ro 9:5) y señaló que en Él habita -corporalmente- toda la plenitud de la Deidad (Col 2:9).

f. Pablo revela la condición divina del Hijo y su igualdad con el Padre (Fi 2:5-8; Col 1:15-17).

g. Cristo es identificado como "Salvador" y "Dios" (Tit 2:13).

h. El Padre se dirige a Jesucristo, y le dice "Tu trono, joh, Dios!" (Heb 1:8). 


\section{La divinidad y persona del Espíritu Santo}

El Espíritu Santo, de acuerdo a las Escrituras, es una de las personas de la Trinidad. A Él se lo presenta como Creador, Maestro, Juez y Guía.

\section{Antiguo Testamento}

a. Estuvo al principio de la creación (Gn 1:2).

b. Se lo revela como el "Creador" (Job 33:4; Sal 104:30).

c. Era el Juez de Israel (Juec 3:10).

d. Tiene atributos de una persona: habla, instruye, juzga (que implica tener la capacidad para reflexionar y decidir), amonesta, guía, etc. (Juec 3:10; 1 Rey 22:24; Neh 9:20, 30; Sal 143:10).

e. Hay personas que se rebelan contra el Espíritu (Sal 106:33).

Nuevo Testamento

a. Tiene el mismo nivel que las otras personas de la Trinidad (Mt 28:19; 1 Co 13:14).

b. Es igual a Jesucristo y es su Representante aquí en la tierra (Jn 14:16, 26; Hech 16:6, 7).

c. Tiene cualidades de una Persona: habla, guía, enseña, oye, etc. (Jn 16:13).

d. Se lo identifica como Dios (mire el paralelismo entre los versículos 3 y 4 , de Hechos 5).

e. Es el Misionero y delega responsabilidades a sus instrumentos (Hech 8:29).

f. Intercede y ayuda en las debilidades (Ro 8:26, 27).

g. Conoce todo - absolutamente todo- del Padre (1 Co 2:10-11).

h. Por sus paralelismos (común en la literatura hebrea), 1 Corintios 
12:4-6 identifica al Espíritu Santo como una de las personas de la Trinidad.

i. Él reparte los dones espirituales, de acuerdo a su propia voluntad (la cual solo es de prerrogativa divina). Ver 1 Corintios 12:11.

j. El creyente es llamado a tener una comunión con el Espíritu Santo (2 Corintios 13:14).

k. Cada hijo de Dios es llamado a no entristecer al Espíritu (Ef 4:30).

\section{Conclusión}

La Trinidad es una de las verdades relevantes que registra la Escritura. Según lo estudiado, las Tres personas divinas siempre han estado activas a lo largo de la historia. Cristo y el Espíritu Santo son personas divinas, y no fueron creados. Ellos siempre han estado con el Padre.

Dios desea que lo conozcamos más, y lo adoremos en Espíritu y en verdad.

Recibido: 03/03/2016

Aceptado: 03/04/2016 